\title{
ANALYSIS OF SOME METALS IN SOME BRANDS OF TEA SOLD IN KANO, NIGERIA
}

\author{
*M.I. Mohammed and M.A. Sulaiman \\ Department of Pure and Industrial Chemistry, Bayero University, P.M.B. 3011, Kano \\ *Correspondence author
}

\begin{abstract}
Tea leaves can be a source of mineral components and trace elements as well as some undesirable substances due to exposure to the environment. In this study, Mg, Fe, Ca, Zn, Mn, Cu and Pb were analyzed by Atomic Absorption spectrophotometer (AAS), $K$ and $N a$ were also determined by flame photometer. Among the metals analyzed, $K$ was the most abundant, ranging from $30.00 \mathrm{mg}^{-\mathrm{dm}^{3}}$ in china sample to $34.60 \mathrm{mg} / \mathrm{dm}^{3}$ in Srilanka sample, followed by $\mathrm{Mg}$ with $9.03 \mathrm{mg} / \mathrm{dm}^{3}$ in India sample to $9.21 \mathrm{mg} / \mathrm{dm}^{3}$ in Srilanka sample. $\mathrm{Ca}, \mathrm{Mn}, \mathrm{Fe}, \mathrm{Zn}, \mathrm{Na}$ and $\mathrm{Cu}$ were also found in reasonable amounts. Fortunately, toxic heavy metal $(\mathrm{Pb})$ had the lowest concentration in all the tea samples with concentration ranging from $0.04 \mathrm{mg} / \mathrm{dm}^{3}$ in India and Srilanka samples to 0.09 $\mathrm{mg} / \mathrm{dm}^{3}$ in China sample.
\end{abstract}

Keywords: Essential metals, Trace metals, Tea, Kano

\section{INTRODUCTION}

Tea is one of the most consumed beverages in the world and is prepared from the leaves of the shrub Camellia sinensis (Saud and AL-Oud, 2003; Fernandez caceres et al., 2001, Powell et al., 1998). Green and black teas are the two most popular types worldwide. Drying and steaming the leaves produces green tea, black tea is obtained after fermentation process. Considering that an estimated amount of 18-20 billion tea cups are consumed daily world wide (Fernandez Caceres et al., 2001; Kirk - Othmer, 1995). Its economic and social interest is clear. Tea has a recognized therapeutic value. It is important in the prevention and treatment of many diseases due to its antibacterial and antioxidant property (FernandezCaceres et al., 2001).

Many elements present in food at major, minor and trace levels are reported to be essential to man's well being. However, their ingestion in excessive amount can cause severe health problems (Kumar et al., 2005). The optimum concentration needed for this purpose varies widely depending on the kind of element and the age and sex of consumers (Ahmed et al., 1989). Human body requires both metallic and non-metallic elements for healthy growth, development and the proper functioning of the body. The determination of these elements in beverages, water, food, plant and soil is thus of utmost importance and is currently the subject of studies by various researchers (Saud and Al-Oud, 2003; WHO, 1998a; b). The study of trace elements in tea has been taken up as trace elements play important roles in the complex metabolic pathways in human system and their deficiencies or excesses may cause diseases (Powell et al., 1998).

Several attempts have been made by many researchers to assess tea quality by chemical analysis usually with reference to pigmentation and the flavoring characteristics. However, to date little work has been done to identify the metal containing components of tea due to the analytical difficulties associated with both the separation of such components and their quantitative measurement (Saud and AL-Oud, 2003). Metallic constituents of tea leaves are normally different according to the type of tea (green or black) and geographical sources (Fernandez cancers et al., 2001; Marcos et al., 1996).

Sahito et al. (2005) reported the contents of fifteen essential trace and toxic elements in some green tea samples and in their infusion. Karimi et al. (2008) worked on the concentrations and health risk of metals in tea samples marketed in Iran. The objective of this research was to determine the mineral elemental composition of different brands of tea sold in Kano markets, with a view to avail both researchers and consumers with information on the mineral contents of the different brands to assist them in choosing which is the best suited for intended use.

\section{MATERIALS AND METHODS}

All the solvents and reagents used were of Analar grade. Distilled water was used as solvent for solution preparation and all glasswares were washed, cleaned and dried in an oven at $105^{\circ} \mathrm{C}$.

\section{Sample Collection}

The samples of dried tea leaves which are commonly consumed were obtained from Dala Food Nigeria Ltd (India, Srilanka) and Kano central market (China, Kenya and Mambilla).

\section{Sample Treatment}

The dry tea leaves were crushed using pestle and mortar. They were crushed and sieved repeatedly to pass through a $2 \mathrm{~mm}$ sieve. The powder was stored at room temperature in dry, air-tight containers for analysis (AOAC, 1984). 


\section{Analytical Procedure}

One gram (1g) of each tea sample was digested using $12 \mathrm{~cm}^{3}$ of a mixture $(3: \mathrm{I} \mathrm{v} / \mathrm{v})$ of concentrated $\mathrm{HNO}_{3}$ and $\mathrm{HClO}_{4}$ acids. Analar grade reagents were used for the preparation of the standard solutions of these metals using their nitrate salts ( $\mathrm{Ca}, \mathrm{K}, \mathrm{Na} \mathrm{Mg}, \mathrm{Mn}, \mathrm{Pb}$, $\mathrm{Cu}, \mathrm{Fe}$ and $\mathrm{Zn}$ ) (Ayodele et al., 1998). The diluted digests were analyzed using flame photometer for $\mathrm{Na}$ and $\mathrm{K}$, while atomic absorption spectrophotometer (AAS) was used for $\mathrm{Mg}, \mathrm{Mn}, \mathrm{Ca}, \mathrm{Pb}, \mathrm{Cu}, \mathrm{Fe}$ and $\mathrm{Zn}$. The metal concentrations in the tea samples were read from standard curves by extrapolation.

\section{RESULTS AND DISCUSSION}

The concentrations of the metals in each tea leaf samples are shown in Figures 1- 9. The results showed that these plants have the ability to accumulate essential and trace metals. Potassium was the element with high content in all the tea samples analyzed (Figure 1) with a mean of $33.1 \mathrm{mg} / \mathrm{dm}^{3}$ and concentration ranging from 30.00 to $34.60 \mathrm{mg} / \mathrm{dm}^{3}$ and co-efficient of variation $36.8 \%$. The distribution pattern shows high concentration in sample Srilanka and low concentration in sample China. Kazi et al. (1999) determined K in tea leaf samples and found it to range from 23.01 to $34.62 \mathrm{mg} / \mathrm{dm}^{3}$. Potassium is important for reducing blood pressure and also increasing blood circulation as well as preventative aid on general health (Kazi et al., 1999).

Calcium, which is the most common mineral in the body, helps in the transport of long chain fatty acids, which aid in prevention of diseases, high blood pressure and other cardiovascular diseases. The obtained calcium levels are shown in Fig 2 with a mean of $3.11 \mathrm{mg} / \mathrm{dm}^{3}$ ranging from $2.08 \mathrm{mg} / \mathrm{dm}^{3}$ in Mambilla samples to $4.58 \mathrm{mg} / \mathrm{dm}^{3}$ in China samples with a coefficient of variation of 18.2 percent. These concentrations were lower than those reported by Kazi et al. (1999) and were higher than those reported by Syed and Qadiruddin (1993).

The levels of sodium in the tea leaf samples range from 0.61 to $4.14 \mathrm{mg} / \mathrm{dm}^{3}$, with a mean of 2.50 and coefficient of variation 26.6 percent (Figure 3), which were lower than those described in the literature (Syed and Qadiruddin (1993). Sodium is the major cation in blood and extracellular fluid (Syed and Qadiruddin (1993).

Magnesium works with calcium to help transmitting nerve impulse in the brain. Both elements give relief in patients having depression (Powell et al., 1998). Fig 4 shows the distribution pattern for $\mathrm{Mg}$ in the tea leaf samples with a mean of $9.12 \mathrm{mg} / \mathrm{dm}^{3}$, range of 9.03 to $9.19 \mathrm{mg} / \mathrm{dm}^{3}$ and coefficient of variation 1.70 percent. The results obtained for the magnesium compares favorably with the values reported by Kazi et al. (1999).
Zinc is important in metabolic function and for growth in man. It forms part of the teeth (Kazi et al., 1999). Fig 5 shows the distribution pattern for $\mathrm{Zn}$ in the tea leaf samples with a mean of $2.17 \mathrm{mg} / \mathrm{dm}^{3}$, range of $0.85-3.07 \mathrm{mg} / \mathrm{dm}^{3}$ and coefficient of variation of 21.6 percent. Mambilla sample had the lowest content while China sample had the highest content comparing with the results of Tahir et al. (2008), the results obtained were generally higher.

Manganese is present in all the tea leaf samples, ranging from 3.00 to $3.84 \mathrm{mg} / \mathrm{dm}^{3}$ with a mean $3.38 \mathrm{mg} / \mathrm{dm}^{3}$ and coefficient of variation 8.00 percent. The distribution pattern shows low concentration in sample Mambilla and India and high concentration in sample China Fig. 6 and were found to be lower than those described in other studies (Powell et al., 1998; Fernandez caceres, 2001). However the values are higher than those reported by Tahir et al. (2008) who reported a range from 0.52 to $1.9 \mathrm{mg} / \mathrm{dm}^{3}$ ). On the other hand, these values were within the range limit $\left(1.95-4.5 \mathrm{mg} / \mathrm{dm}^{3}\right)$ reported by Saud and Al - Qud (2003).

Figure 7 shows the distribution pattern of iron, with a range of $2.00-4.40 \mathrm{mg} / \mathrm{dm}^{3}$, and a mean value of $3.19 \mathrm{mg} / \mathrm{dm}^{3}$ and coefficient of variation of 20.8 percent. In the present study, iron levels were between 0.020 and $0.128 \mathrm{mg} / \mathrm{dm}^{3}$. The bioavailability of this element is influenced by polyphenol found in tea that can markedly inhibit the absorption of iron (Karimi et al., 2008). The copper contents in investigated tea samples ranged from 0.20 to 0.4 $\mathrm{mg} / \mathrm{dm}^{3}$ with the mean of $0.3 \mathrm{mg} / \mathrm{dm}^{3}$ and coefficient of variation 1.90 percent (figure 8 ). The obtained results showed higher values than those values $\left(0.16 \mathrm{mg} / \mathrm{dm}^{3}\right)$ reported by Saud and Al - Qud (2003) and lower than the $\mathrm{Cu}$ contents $\left(0.52 \mathrm{mg} / \mathrm{dm}^{3}\right)$ reported by Karimi et al. (2008). The variation of $\mathrm{Cu}$ content in the tea could be attributed to different types, grade and producing areas of the teas. $\mathrm{Cu}$ pollution could be mainly from the rolling machine and fungicides (Han et al., 2006). The concentration of lead $(\mathrm{Pb})$ in tea leaf samples was presented in Fig. 9 with a mean of $0.056 \mathrm{mg} / \mathrm{d}^{3}$, range of 0.04 to 0.09 $\mathrm{mg} / \mathrm{dm}^{3}$ and coefficient of variation of 0.4 percent. The main sources of $\mathrm{Pb}$ in tea samples could be their growth media, such as soil. Pb contamination in soil usually can be attributed to industrial activity (smelting process), agricultural activities (application of insecticides) and urban activities (combustion of gasoline). Tea plant is normally grown in high acidic soils where $\mathrm{Pb}$ is more bioavailable for root uptake. Deposits from the polluted air into the leaves of the plant can be another source of $\mathrm{Pb}$ contamination of tea (Han et al, 2006). 

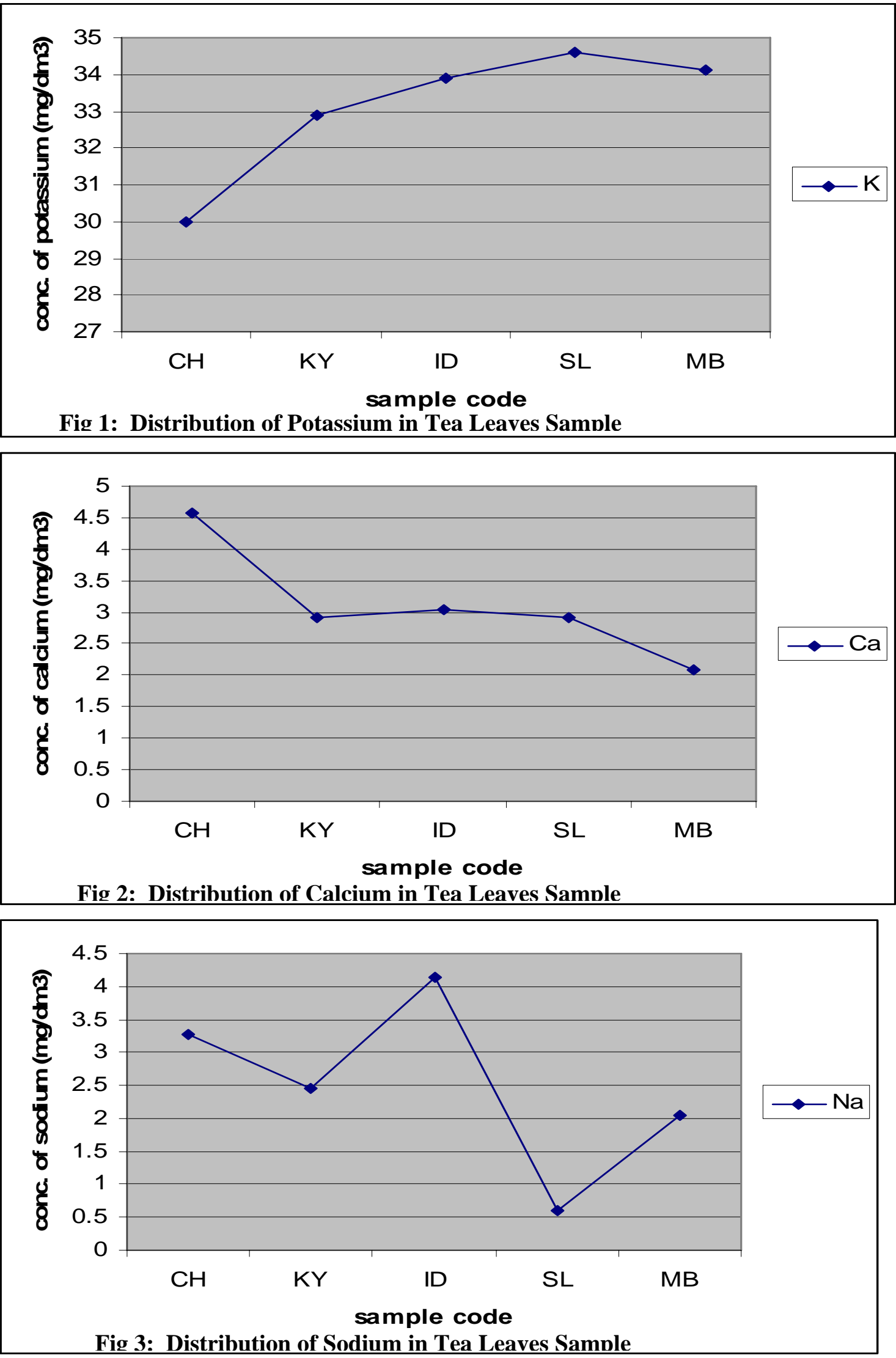

KEY: $\mathrm{CH}=\mathrm{CHINA}, \mathrm{KY}=\mathrm{KENYA}, \mathrm{ID}=\mathrm{INDIA}, \mathrm{SL}=$ SRILANKA, MB=MAMBILA 
Bajopas Volume 2 Number 2 December, 2009
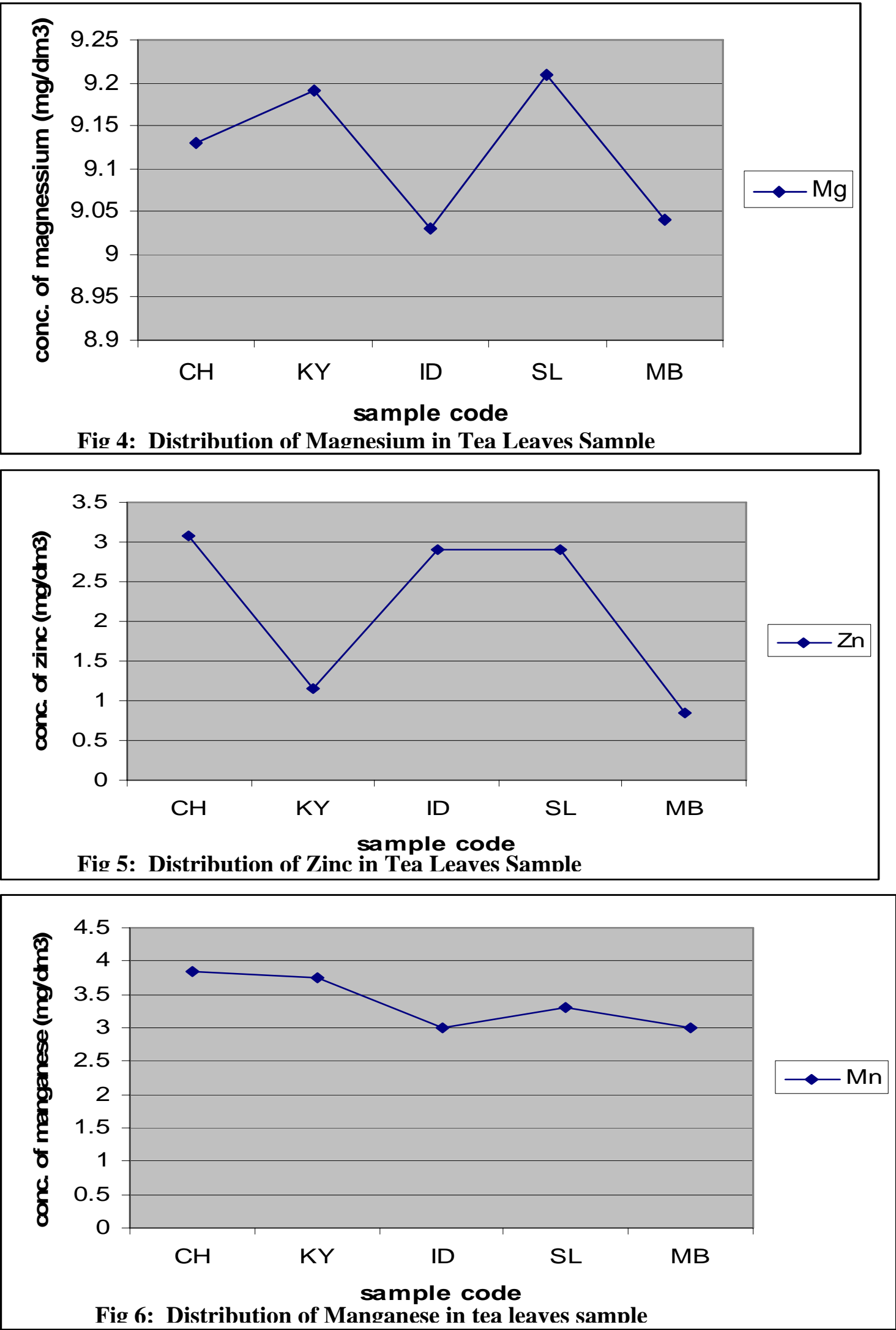

KEY: $\mathrm{CH}=\mathrm{CHINA}, \mathrm{KY}=\mathrm{KENYA}, \mathrm{ID}=\mathrm{INDIA}, \mathrm{SL}=\mathrm{SRILANKA}, \mathrm{MB}=$ MAMBILA 
Bajopas Volume 2 Number 2 December, 2009
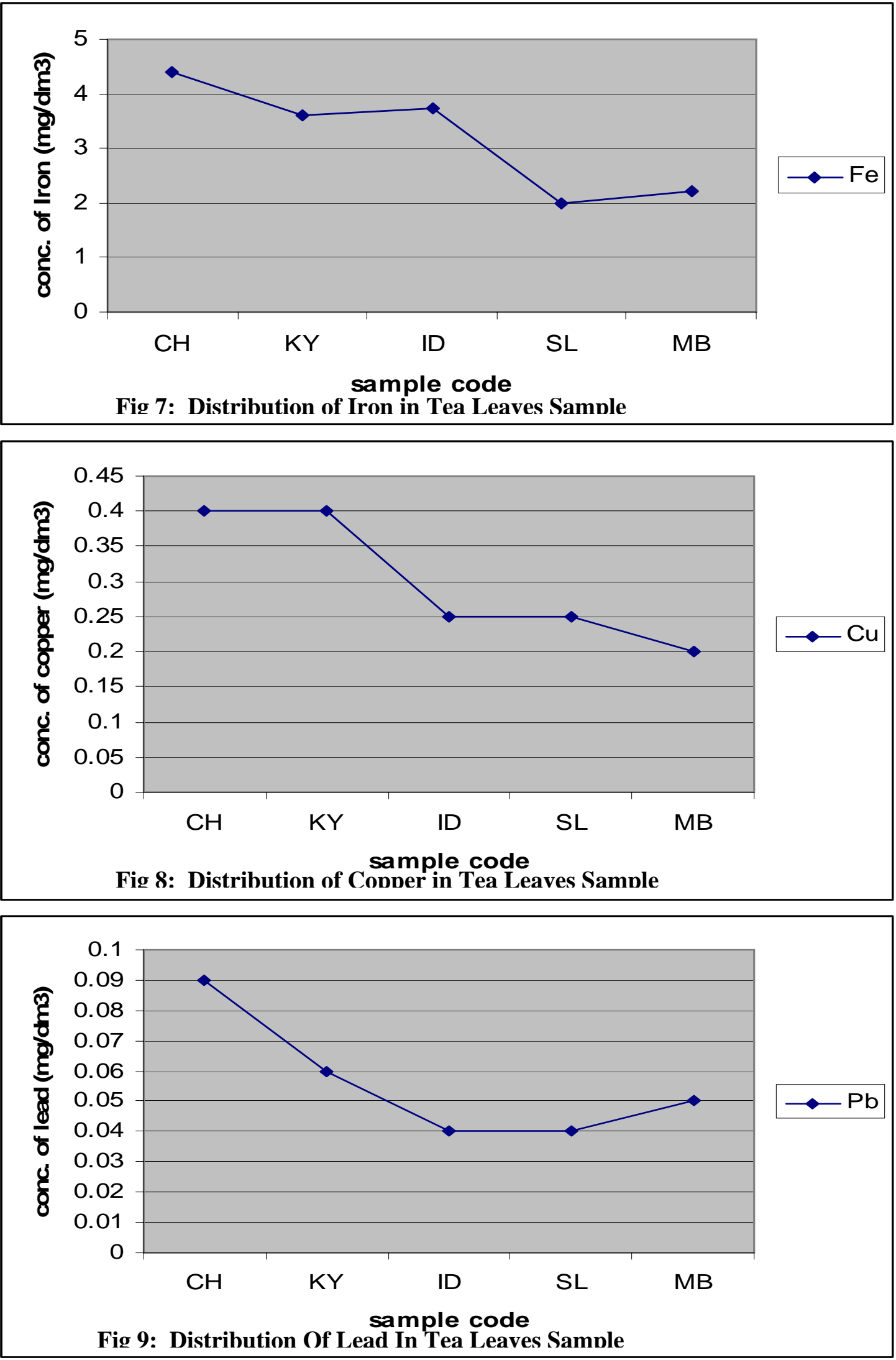

KEY: $\mathrm{CH}=\mathrm{CHINA}, \mathrm{KY}=\mathrm{KENYA}, \mathrm{ID}=\mathrm{INDIA}, \mathrm{SL}=$ SRILANKA, MB=MAMBILA 
Bajopas Volume 2 Number 2 December, 2009

\section{CONCLUSION}

The results of this work show that tea serves as one of the sources of human intake of various metallic elements, which are essential for growth. The

\section{REFERENCE}

Ahmed, I., Zaidi, S.S.H and Khan, Z.A. (1989). The determination of major, minor and trace elements in tea, tea liquor, instant coffee and cocoa samples. Pak. J.Sci Ind. Res., 32 (8): 513-515.

AOAC (1984), Official method of analysis of the association of official analytical chemists (AOAC) $14^{\text {th }}$ edition. Washington, D.C.USAP Pp.152-162.

Ayodele J.T., Garba S.D. and Garki Y. (1998) Characteristics and Composition of cassia for a linn seed and oil, Nigerian Journal of Palm Oil Seeds Pp. 76-79.

Fernandez-Caceres, P.M.J., Martin, M.P. and Gonzalez, A.G. (2001). Differentiation of tea (Camellia sinensis) varieties and their geographical origin according to their metal content. J. Agric. Food Chem., 49: 4775-4779.

Marcos, A., Fisher, A. Ree, G. and Hill, S.J. (1996). Preliminary study using trace element concentration and a chemometrics approach to determine the geological origin of tea. J. Agric. Atom. Spect, 113:521-525.

Powell, J.J., Burden, T.J. and Thompson, R.P.H. (1998). In vitro mineral availability from digested tea: A rich dietary source of manganese. Analyst, 123:17211724.

Sahito S.R., Kazi, T.G. Jakharani, M.A. Kazi, G.H. Shar, Q.G. and Shaikh, S. (2005) The contents of fifteen essential, trace and toxic elements in some green tea samples and in their infusion. Tour. Chem. soc. Pak. 27(1):43-47.

Saud, S. and AL-Oud, (2003). Heavy metal contents in tea and herb leaves. Pak. J. Bio1. Sci., 6: 208-212. preliminary studies on lead also indicated that though it is present at a measurable level no immediate threat is posed.

Han, W.Y., Liang, Y.R., Yang, Y.J., Ma, L.F. and Ruan, J.Y. (2006), Effect of processing on the $\mathrm{Pb}$ and $\mathrm{Cu}$ pollution of tea in Chinese. J Tea Sci 26: 95-101.

Karimi, G., Hasanzadeh, M. K., Nili, A., Khashayarmanesh, Z., Samiei, Z., Nazari, F. and Teimuri, M. (2008) Concentrations and Health Risk of Heavy Metals in Tea Samples Marketed in Iran. Pharmacologyonline 3: 164-174

Kazi T.G, G.H. Kazi and T.P. Ansari (1999). J. ACGC, 9, 51

Kirk- Othmer, S. (1995). Encyclopedia of chemical Technology. $4^{\text {th }}$ Edn. A Wiley- nescience publication, John Wiley and Sons. Vol, 23.

Kumar, A., Nair, A.G.C. Reddly, A.V.R. and Garg, A.N. (2005). Availability of essential elements in India and US tea brands. Food Chem., 89: 441-448.

Tahir, S.M., Zahir, E. Mohiuddi, S. Nisar, K A. and Naqvi, I.I (2008). Quantitative Assessment of metals in local Brands of tea in Pakistan. Pak.J Bio. Sci. 11(2): 285-289.

WHO (1998a), Guidelines for Drinking Water Quality. $2^{\text {nd }}$ Edn. Health criteria and Other Supporting Information. World Health organization, Geneva, pp: 47-61. Web search WHO guidelines for drinking water quality.

WHO (1998b), Guidelines for Drinking Water quality. $2^{\text {nd }}$ Edn. Health Criteria and Other Supporting Information, World Health Organization, Geneva, pp: 308-313. Web search WHO guidelines for drinking water quality. 